\title{
Analysis and research of credit evaluation system for B2B e-commerce platform
}

\author{
Zhuang Yu-feng \\ Beijing University of Posts and Telecommunications \\ Beijing 100876, China \\ e-mail: zhuangyf@bupt.edu.cn
}

\author{
Zhang Yan \\ Beijing University of Posts and Telecommunications \\ Beijing 100876, China \\ e-mail: haozhangyan@163.com
}

\begin{abstract}
This paper analyzes the current development situation of domestic B2B e-commerce platform, and optimizate credit evaluation system from several aspects. In addition, this article also put forward that enhancing credibility by introducting the internet financial system. Aimed to ensure the safety of both sides' transaction funds, and further improve the credit evaluation system of B2B ecommerce platform.
\end{abstract}

Keywords-B2B e-commerce platform; Credit evaluation system; Internet finance Introduction

B2B (Bussiness-to-Bussiness) E-commerce refers to the both sides of supply and demand between e-commerce transactions are businesses. They complete the business transaction process, by using Internet technology or business networking platform. These processes include: publish supply and demand information, order and confirm order, pay and bill issuance process, transmit and receive, determine the distribution plan and monitor the distribution process, delivery and so on. The above processes can be done directly between the vendors and also can be completed by an independent third-party platform. So, the key reason to choose the latter is that the third-party service providers must be trustworthy.

\section{THE CURRENT SITUATION OF B2B E-COMMERCE PLATFORM}

According to iResearch released "The q1 2013 yearly data of small and medium-sized enterprises' B2B ecommerce in China", as shown in figure 1. Q1 2013 China's e-commerce market overall size is 220 million yuan, fell 6.8\%, year-on-year growth of $24.7 \%$. Meanwhile $^{[1]}$, Q1 2013 revenue size of small and mediumsized enterprise B2B e-commerce market reached 4.62 billion yuan, up 20.6\% from a year earlier. Until Q2 2013, the small and medium-sized enterprise B2B e-commerce of China total revenue of 4.96 billion yuan, up $19.2 \%$ yearon-year, rose $7.4 \%$.

Thus it can be seen, China's B2B e-commerce is booming, and the construction of a collection of information service, transaction service, resources integration into an integrated whole B2B e-commerce platform has wide development prospects. E-commerce trading platform occupies an important position in the transaction, is the intermediate links between buyers and sellers. Besides self-built e-commerce of some enterprises, most enterprises, especially small and medium-sized enterprises are relying on e-commerce trading platform for trading. From the point of current B2B development situation at home and abroad, provide a neutral trading service by third parties to create common B2B platform is the main driver of $\mathrm{B} 2 \mathrm{~B}$ e-commerce market, because it is attractive to both buyers and sellers, and can be broad enough to release and share information in the field as well as cooperation.

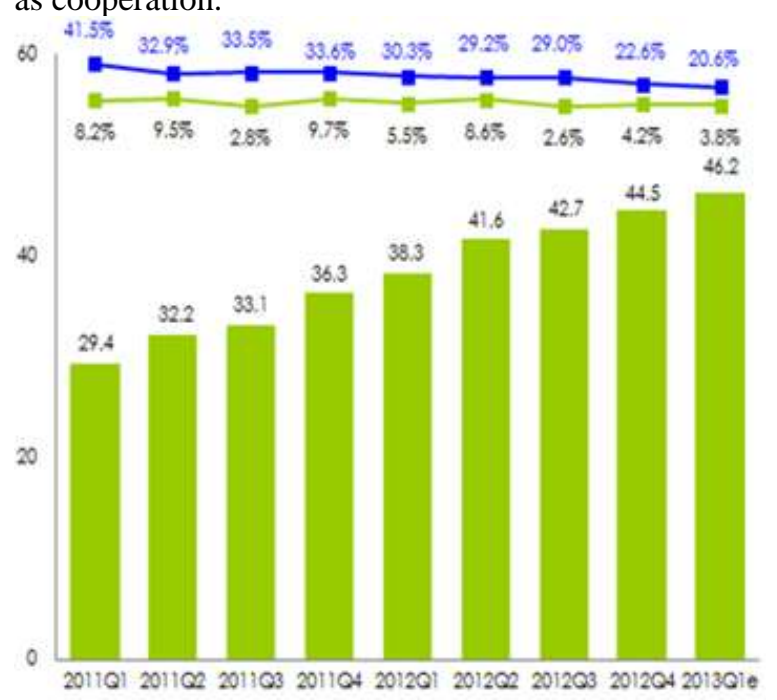

Figure 1. B2B e-commerce annual data of China's small and mediumsized enterprise

The present leading $\mathrm{B} 2 \mathrm{~B}$ e-commerce platform at domestic market mainly include Global Sources, DHgate, HC360, Alibaba, Made-in-Chinacom, etc. B2B ecommerce participants can be simply divided into suppliers, purchasers and services. The third-party B2B ecommerce platform is one of the services, its main characteristic is to provide information and trading platform for both the supply and the demand. The enterprise of trading platform itself is not involved in the production and procurement, as well as not to participate in the trading process ${ }^{[2]}$. The offering services can be divided into three categories: information service, transaction service and resource integration. Enterprise witch represent Providing information services is Global Sources, DHgate and 315.com mainly provide trade services, Alibaba is the representative of offering integration services.

\section{THE PARTICULARITY OF B2B E-COMMERCE PLATFORM}

Compared to $\mathrm{C} 2 \mathrm{C}$ e-commerce credit evaluation system, B2B e-commerce platform itself also has some special advantages. Such as the seller of $\mathrm{C} 2 \mathrm{C}$ transactions 
will use a loophole in the current rules for raise the hype of the credit, in order to rapidly improve their credit. It is largely because $\mathrm{C} 2 \mathrm{C}$ belongs to the category of driblet transaction $^{[3]}$, the transfer of funds is relatively easy and lack of regulation. And B2B e-commerce transaction amount is larger, usually if coupled with the third party capital regulation it can easily avoid the above situation happened.

However, cause objects of the transaction at B2B ecommerce platform are mainly commodities, single purchase order amount usualy very large. And it needs to be based on $\mathrm{O} 2 \mathrm{O}$ business operation mode(online information transactions and offline entities interactive combination). So there are more unknown factors and uncertainties, and the subsequent transaction risk is obvious.

\section{THE PROBLEMS IN THE CREDIT EVALUATION RULES OF B2B E-COMMERCE PLATFORM}

In the process of trading, the credit evaluation rules of most B2B e-commerce sites having loopholes and defects. For instance, some sites did pretty good on the seller's integrity management, but for the buyer the regulation is more weak ${ }^{[5]}$. Although scores can be used in evaluating buyers' integrity, but in the existing iterms of service, the platform more inclined to protect the rights and interests of the buyer (such as the buyer don't have to use real-name in their registration and purchases, refusing to receive the goods is permissible, and platform will not give sellers the payments for the their goods, etc). If the binding for buyers is not strong, it will be more easily to bring bigger risk to the seller, such as the mat endowment risk before receive payment, and the freight risk bring by the buyer's behavior of break a contract.

If such problems occur, it will be affect the enthusiasm of businessmen to use the platform in a certain extent. So a perfect credit evaluation system is needed to establish for the current $\mathrm{B} 2 \mathrm{~B}$ e-commerce platform, to minimize the losses caused by the occurren risk and to take it seriously and plan ahead.

\section{THE OPTIMIZATION OF CREDIT EVALUATION SYSTEM}

\section{A. Strengthen the certification audit before entry}

Now many of the third party e-commerce transaction platform simplify the registration process, in order to increase the number of users as soon as possible. It significantly reduces the platform barriers to entry. This way may attract a large number of users or enterprises to use the platform in a short term, but in the long run it is not reasonable. Low barriers directly lead to the phenomenon of the users appear the good and bad are intermingled ${ }^{[6]}$. A lot of companies with completely certification and creditworthy will soon found the service provided has little value, and even cause the direct economic losses. When that keeps happening, the precipitated users of platform will also dramatically reduced.

The platform should to ensure the information authenticity and do a good job of information review and identity authentication before enterprise users (buyers and sellers) registed as a platform members. The review contents should include business license, business certificate or production license, the power of attorney and legal person id photocopy, etc. In addition, the platform can help members to complete the CA certification, only through the CA certification can the traders publish trading information to the platform. In order to ensure the authenticity of trading business company and any operating in the trading platform has the force of law. Finally, all the traders also should make a market agreement with platform, with statement of responsibilities and rights, and done in duplicate.

\section{B. The third party inspection and the third party logistics}

The third party mentioned here refers to a third- party providing services, other than the buyers and sellers of platform. Same as the platform, the third party itself is also not participate in the trading process, So it can completely as an arbitration institution to supervise the trading behavior of the buyers and sellers in the process of trading. And To ensure there are no problems in their credit ${ }^{[7]}$.

Cooperation with the third party inspection agencies to prevent problems of both side dispute on goods quality, and to be justified when dispute occurs. On the other hand, B2B e-commerce from online transactions to offline entities transportation cannot be separated from logistics. The best mode of logistics is to cooperate with third party logistics, because the cost of self-built logistics is too expensive. So it's very important to select an advanced third party logistics enterprise. This approach can improve the efficiency and effectiveness of the B2B e-commerce, as well as more able to ensure the fair dealing in the aspect of logistics.

Of course, the cooperation with the third party should be based on "contract relationship". On one hand to clear rights and responsibilities of both sides, on the one hand, personalized service plan should be made for the users too. For example, the role of third party logistics is primarily as a platform to provide logistics services, and to ensure integrity in the transport of goods ${ }^{[8]}$; However, platform should do more, such as designing an available and specific information system on the basis of a certain algorithm to integrate these third-party logistics enterprises. And presented to the platform users that they can choose many different plans for what they want, So eventually let the user to optimize the selection, realizing the intelligent of logistics.

\section{The capital regulation of Internet financial}

With the development of B2B e-commerce platform, in addition to a small number of state-owned large and medium-sized enterprises, most of the trading behavior is still done between small and medium-sized enterprises. However, credit rating system in China, almost all focuse on the securities market of state-owned large and mediumsized enterprises. Small and medium-sized enterprise credit system, especially the growth of small and mediumsized enterprise credit system has not yet been fully established. Therefore, bank credit business is constantly subject to the conditions of credit rating, not smooth loans to small and medium-sized enterprises. Small and medium-sized enterprises financing is still facing the huge challenge. 
The generation of Internet financial make it possible to thoroughly solve the problem of small and medium-sized enterprise financing. Customers' Operating conditions and credit rating reflected by their surfing behavior and transaction records on the Internet trading platform. Electric business platform own the detailed data of merchant's operating status and financial situation ${ }^{[9]}$. Through a variety of weight calculation model for its credit rating, and gives the corresponding credit lines. And there are a long period of cash flows with its own payment terminal services, so it is controllability for the financing risk. Thus realized the financial capital of internet regulation. Relying on the credit accumulation system and transaction record in the platform, enterprise as a legal person can apply for a certain amount of loans, and does not require any collateral. That is to say, excepted for the requirement of big data, all of which must be based on perfect credit rating system.

On the one hand, B2B e-commerce platform can rely on a third party credit rating agencies to provide the enterprises' credit rating data; On the other hand, its itself as a independent third party in the deal, can also set up its own credit rating system. Thus, the rating results can be an important reference of credit decisions for financial institutions. Providing differentiated services in terms of loan services, to promote the percentage of successful transactions between the small and medium-sized enterprises and to enhance their own credibility. Thus, to further improve the impaction of platform and the transaction success rate, as well as to increase the credibility of e-commerce platform.

\section{Reference of $\mathrm{C} 2 \mathrm{C}$ credit evaluation rules}

Now domestic C2C e-commerce platform has developed quite mature, therefore in the subsequent stages of $\mathrm{B} 2 \mathrm{~B}$ e-commerce transactions, the personal credit evaluation model of $\mathrm{C} 2 \mathrm{C}$ e-commerce platform can be referenced, to complete "Score Power" between enterprises of the seller and the buyer. For example, for Internet sellers, the evaluation can be done as the below aspects: the degree of match between products and description, the effectiveness of communication, the speed of delivery, transaction value of the weighted integral, and the number of successful transaction, etc.; For buyers, although the evaluation parameters is relatively small, in order to ensure the fairness, the evaluation can be separated as the speed of transfer funds, transactions have any fraud, the speed of the receipt goods, and the number of successful transaction. This credit evaluation method is a credit evaluation tool used to measure information of traders as well as collecting and statistics of traders' trading credit level. It can describe the trader's credit level from various angles ${ }^{[10]}$. The credit evaluation model are shown in Figure 2 below, the core of the credit trading is "mutual".
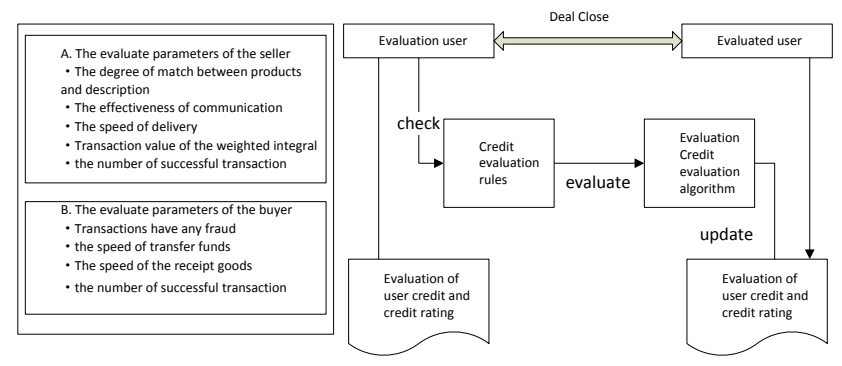

Figure 2. The mutual model of B2B e-commerce platform

\section{CONCLUSIONS}

This paper points out the existing trust problems between the buyers and sellers in the actual transaction process. Further optimized credit evaluation system from the following aspects, such as standardizing members' early registration, introducing the third party system of trust, setting up the mutual model, and so on. Creatively put forward that enhancing credibility by bring in financial capital regulation under the environment of Internet finance, to ensure the safety of both sides' transaction funds, and further improve the credit evaluation system of B2B e-commerce platform.

Whether buyer-dominated market or not, as a third party service platform, fair and just is necessary, so it be able to get a long-term development and progress. On the basis of using perfectly with its own platform credit rules, B2B e-commerce platform make the best use of third-party authority supervision and service, and coupled with the capital regulation of internet financial, the credit rating agency's credit evaluation audit system can be in the whole transaction chain as reliable long-term development.

It should be noted that the current credit system in our country is still not perfect, the related law has not yet complete about internet financial, the cost of financial default is low, and it is still easy to induce malicious fraud risk problem such as run away with money and malicious fraud. Therefore, you cannot rely solely on the data provided by the third party credit rating agencies, it's more important to improve the platform's own supervision, such as establishing first-class risk control system and professional team of risk control, etc.

\section{REFERENCES}

[1] Liu xin. Promoting effect of internet financial for small and medium-sized enterprises financing[J]. Xi Jiang yue, 2013,42(34).J. Clerk Maxwell, A Treatise on Electricity and Magnetism, 3rd ed., vol. 2. Oxford: Clarendon, 1892, pp.68-73.

[2] Wang Tian-jie, Zhang Yi-cheng. Financing problems research of small and medium-sized enterprise based on Internet financial model[J]. China Market, 2013(45):134-136.

[3] Meng Xiang-mei. SWOT analysis of DHgate.com for B2B2.0 ecommerce model[J]. China E-commerce, 2012(13):14.

[4] Pang Yuan-chao. Research overview of useing B2B e-commerce[J]. Cuide to Business, 2011(19):168-169.

[5] Piao Chun-hui, An Jing, Fang Mei-qi, Research of credit evaluation model and algorithm for $\mathrm{C} 2 \mathrm{C}$ e-commerce[J], Journal of Information, 2007.

[6] DING S, LI X. Research and Analysis of Seller's Dynamic Credit Evaluation Model in Online Shopping[J]. Computer Technology and Development, 2013, 5: 5. 
[7] Song X D, Han L Y. Credit Evaluation for Small-and-MediumSized Enterprises Based on Fuzzy SVM with Dual Membership Values[J]. Industrial Engineering Journal/Gongye Gongcheng, 2012,15(1).

[8] Jiang Y, Gong H. Commercial Credit Value Evaluation and Illustration Analysis on Internet[M]//Advanced Research on Electronic Commerce, Web Application, and Communication. Springer Berlin Heidelberg, 2011: 70-75.
[9] Zhou X, Jiang W, Shi Y. Credit risk evaluation by using nearest subspace method[J]. Procedia Computer Science, 2010, 1(1): 24492455 .

[10] Doumpos M, Zopounidis C. Credit Scoring[M]//Multicriteria Analysis in Finance. Springer International Publishing, 2014: 43 59. 